\title{
Variations in Friction Velocity with Wind Speed and Height for Moderate-to-Strong Onshore Winds Based on Measurements from a Coastal Tower
}

\author{
PINGZHI FANG \\ Shanghai Typhoon Institute of China Meteorological Administration, Shanghai, China \\ WENDONG JIANG \\ State Grid, Zhejiang Electric Power Co., LTD, Zhejiang, China \\ JiE TANG AND XiAOTU LEI \\ Shanghai Typhoon Institute of China Meteorological Administration, Shanghai, China \\ JIANGUO TAN \\ Shanghai Climate Center, Shanghai Meteorological Service, Shanghai, China
}

(Manuscript received 6 December 2018, in final form 5 December 2019)

\begin{abstract}
Variations in friction velocity with wind speed and height are studied under moderate $\left(\geq 9 \mathrm{~m} \mathrm{~s}^{-1}\right)$-to-strong onshore wind conditions caused by three landfalling typhoons. Wind data are from a coastal 100-m tower equipped with $20-\mathrm{Hz}$ ultrasonic anemometers at three heights. Results show that wind direction affects variations in friction velocity with wind speed. A leveling off or decrease in friction velocity occurs at a critical wind speed of $\sim 20 \mathrm{~m} \mathrm{~s}^{-1}$ under strong onshore wind conditions. Friction velocity does not always decrease with height in the surface layer under typhoon conditions. Thus, height-based corrections on friction velocities using the model from Anctil and Donelan may not be reliable. Surface-layer heights predicted by the model that are based on Ekman dynamics are verified by comparing with those determined by a proposed method that is based on the idea of mean boundary layer using wind-profile data from one of the landfalling typhoons. Friction velocity at the top of the surface layer is then estimated. Results show that friction velocity decreases by about $20 \%$ from its surface value and agrees well with previous results of Tennekes.
\end{abstract}

\section{Introduction}

Several methods have been developed to calculate air-sea momentum flux exchange. The bulk transfer method has been widely employed because of its convenience by using the drag coefficient (Fairall et al. 2003; Zeng et al. 2010; Edson et al. 2013). As pointed out by Guan and Xie (2004), self-correlation is frequently encountered in studying the variation in drag coefficient with wind speed. According to the bulk transfer method, momentum flux can be calculated as

$$
\tau=\rho_{a} C_{D 10, n} u_{10, n}^{2}=\rho_{a} u_{*}^{2},
$$

Corresponding author: Pingzhi Fang, freedomfpz@163.com where $\rho_{a}$ is the density of air; $C_{D 10, n}$ and $u_{10, n}$ are the drag coefficient and wind speed, respectively, at $10 \mathrm{~m}$ above the sea surface under neutral conditions; and $u_{*}$ is the friction velocity. The above equation indicates that momentum flux can be obtained from friction velocity if a relationship between $u_{10, n}$ and $u_{*}$ has been established, with no need to obtain the relationship between $u_{10, n}$ and $C_{D 10, n}$. Several studies have showed that $u_{10, n}$ and $u_{*}$ are well correlated and that the relationship between them can be expressed using piecewise linear functions (Foreman and Emeis 2010; Andreas et al. 2012; Edson et al. 2013). Wind data in the above studies were collected from the open-ocean and nearshore sites. However, the nearshore measurements of Zhao et al. (2015) and the open-ocean measurements of Jarosz et al. (2007) indicate that $u_{*}$ levels off or decreases at higher wind speeds. To the best of our knowledge, few studies 
have been conducted on variations in friction velocity at higher wind speeds using coastal wind data, which is one of our focuses in this study.

The boundary layer above the sea surface can be viewed as in three sections. The wave boundary layer is the lowest, adjacent to the sea surface. The atmospheric boundary layer (ABL) is the highest, adjacent to the free atmosphere. Between them is the surface layer, with a mean height of about $100 \mathrm{~m}$. However, the surface layer may reach a height of several hundred meters over the ocean under typhoon conditions (Powell et al. 2003). It becomes more complicated and thicker with an increase in magnitude of $20 \%-30 \%$ for nearshore typhoons (Vickery et al. 2009). Constant friction velocity throughout the surface layer is a fairly restrictive assumption. Most often, friction velocity decreases with height. Anctil and Donelan (1996) proposed a model relating friction velocities at the surface to the measurement height (hereinafter the "A\&D model"). This model was then used to correct the decrease in friction velocity with height at a nearshore site under neutral conditions. French et al. (2007) showed that the stress at the top of the ABL remains about $50 \%-75 \%$ of that at the sea surface (corresponding to about $70 \%-85 \%$ for friction velocity), and that the A\&D model can provide comparable estimates for the decrease of friction velocity with height. Their conclusions were based on aircraft data from mature hurricanes over the open ocean far from the shoreline. Tennekes (1973) also showed that the stress decreases by some $30 \%$ from its surface value (corresponding to about 20\% for friction velocity). Zhang et al. (2009) studied the turbulence structure in the hurricane boundary layer between outer rainbands using the same dataset. Their work showed that thermodynamic boundary layer heights estimated using virtual potential temperature profiles are roughly half those estimated using momentum flux profiles. Therefore, it is necessary to investigate the boundary layer height or structure and variations in friction velocity with height for the more-complicated surface layer at the coastline as typhoons make landfall.

Using high-frequency ultrasonic wind data from a 100$\mathrm{m}$ coastal tower at three heights, variations in friction velocity with wind speed and height are studied under moderate-to-strong onshore wind conditions. A method to determine the surface-layer height in typhoons is proposed using wind profiles from global positioning system (GPS) microsonde data. The GPS-based results are used to test the applicability of the existing model on the surface-layer height. Then, friction velocity at the top of the surface layer in typhoons was estimated using the A\&D model and the surface-layer height from the existing model. Results indicate that friction velocity decreases by about $20 \%$ from its surface value and is quite close to that reported by Tennekes (1973).

\section{Observations and data collection}

The tower is located at a coastal site $\left(24^{\circ} 02^{\prime} 08.556^{\prime \prime} \mathrm{N}\right.$, $117^{\circ} 53^{\prime} 59.3124^{\prime \prime} \mathrm{E}$ ) in Chihu Town, Fujian Province, China, as indicated by point $\mathrm{A}$ in Fig. 1 . The altitude of the site is $29 \mathrm{~m}$. The shoreline is roughly oriented from northeast to southwest, as indicated by the line $\mathrm{B}-\mathrm{A}-\mathrm{C}$ in the figure. Thus, open-sea conditions correspond to wind directions of $45^{\circ}-225^{\circ}$, land conditions correspond to wind directions of $270^{\circ}-360^{\circ}$, and limited-sea conditions correspond to wind directions of $360^{\circ}-45^{\circ}$ and $225^{\circ}-270^{\circ}$. Nearshore isobaths adjacent to point $A$ are shown in the inset in the lower-right corner in Fig. 1. In general, the nearshore isobaths are parallel to the line $\mathrm{B}-\mathrm{A}-\mathrm{C}$. The height of the tower is $100 \mathrm{~m}$. Observational equipment was deployed at heights of 26.6, 42.4, 60.4, and $82.9 \mathrm{~m}$ above ground level (first, second, third, and fourth levels from bottom to top, respectively). Each level contained a Gill Instruments, Ltd., WindMaster Pro ultrasonic anemometer (UA) and a Campbell Scientific, Inc., R.M. Young 05106 wind monitor, with sampling frequencies of 20 and $1 \mathrm{~Hz}$, respectively. The cantilever that supported each pair of instruments pointed east. A barometer at $8.5 \mathrm{~m}$ above ground level and a thermometer and hygrometer at 10 and $70 \mathrm{~m}$ above ground level were also deployed with the output frequency of one data point per minute. More detailed information on the tower and the local topography can be referred to Fang et al. (2018).

Three typhoons, Lionrock (1006), Fanapi (1011), and Megi (1013), made landfall along tracks to the left of the tower in 2010, as shown in the inset in the upperleft corner in Fig. 1. The corresponding landfall times (UTC) were 23001 September, 230019 September, and 050023 October. Their minimum distances from the tower were 33, 40, and $21 \mathrm{~km}$, respectively. Figure 2 shows wind speeds and directions from observations at the fourth level with an averaging time interval (ATI) of $10 \mathrm{~min}$ and for wind speeds higher than $10 \mathrm{~m} \mathrm{~s}^{-1}$ for each typhoon. The wind data in Fig. 2 a have not been subjected to any quality control. The wind direction changed by nearly $180^{\circ}$ when the typhoons made landfall, which implies that the typhoon centers passed close to the tower. The wind data featured by full profiles are shown in Fig. $2 \mathrm{~b}$ and constitute the analysis dataset used in this study. A full profile is one in which wind data were simultaneously obtained and passed the preliminary quality control at the first, second, third, and fourth levels. A preliminary quality control includes a data loss ratio less than $5 \%$ and stationarity 


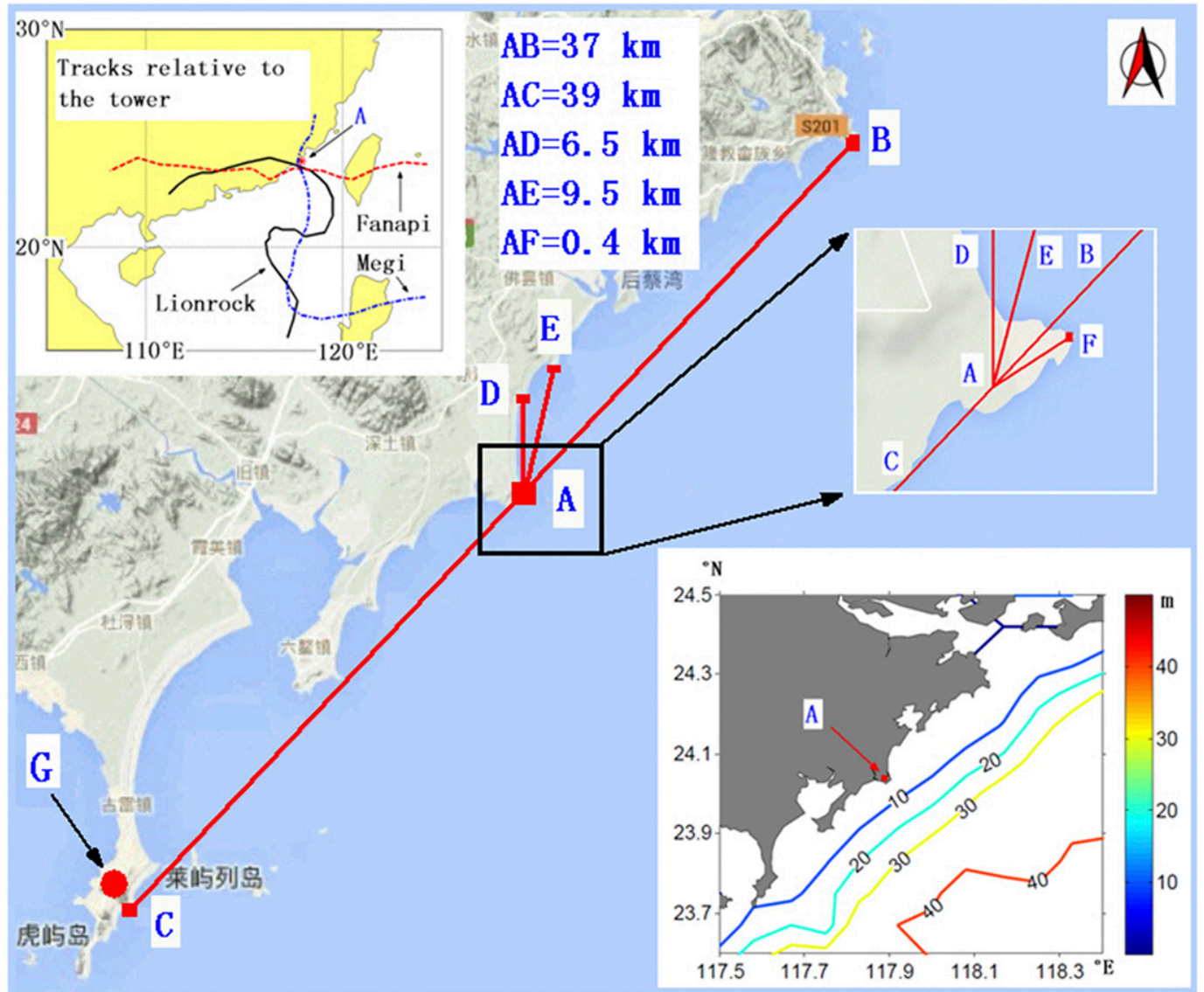

FIG. 1. Location of the coastal site (point A). Lines A-D, A-E, and A-F roughly follow azimuths of $0^{\circ}, 15^{\circ}$, and $60^{\circ}$, respectively. Nearshore isobaths adjacent to point A are shown in the inset at lower-right corner. Tracks of the typhoons are shown in the inset in the upper-left corner. GPS microsondes were released at point G when Fanapi made landfall.

checking by a run test (Fang et al. 2018). The data loss ratio of a sample is defined as the count of the lost data points divided by the one of the maximum possible data points.

\section{Brief description of the data quality control}

A brief description of the data quality-control procedure is provided in this section. More detailed information can be found in Fang et al. (2018).

Wind data with wind directions of $15^{\circ}-210^{\circ}$, which were not influenced by the tower body, were considered to be onshore in this study. The wind fetch over the water was at least $\sim 10 \mathrm{~km}$ for wind directions of $15^{\circ}-45^{\circ}$. According to Mahrt et al. (2003), the land upwind of the water body had little effect on the wind data. Wind data with directions of $210^{\circ}-225^{\circ}$ were removed because of possible disturbance by the shoreline at a geographic azimuth of $225^{\circ}$.

Wind speeds in the horizontal plane from the UAs were compared with those from the wind monitors at the same level. Measurements were nearly identical, suggesting that wind speeds from the UAs are reliable. Sonic temperatures from the UAs were compared with those at the 10- and 70-m levels to evaluate the reliability of the calculated Obukhov lengths. Results indicate that the sonic temperature is affected not only by precipitation, as shown by Zhang et al. (2016), but also by the environmental temperature, which induced the observed abnormalities in sonic temperature from the first and second levels. As a result, the sonic temperature observations from the third and fourth levels were used to calculate the Obukhov lengths for the site.

Effective heights are adopted to describe surface elevation in this situation (Bowen and Lindley 1977). The wind profile for the upper part of the surface layer near the tower, under onshore wind conditions, is assumed to be from the nearshore surface layer:

$$
u_{z}=\frac{u_{*}}{\kappa}\left[\ln \left(z / z_{0, n}\right)-\psi(z / L)\right],
$$


where $u_{z}$ is the observed wind speed at effective height $z$ above the sea surface, which is the sum of the altitude at point $\mathrm{A}(29 \mathrm{~m})$ and the height of the observational equipment above ground level; $z_{0, n}$ is the roughness length induced by sea waves under neutral conditions; $\kappa=0.4$ is the von Kármán constant; and $\psi(z / L)$ is the stability function defined as follows (Dyer 1974):

$$
\psi(z / L)= \begin{cases}-5 z / L, & 0 \leq z / L \leq 0.2 \\ 2 \ln [(1+X) / 2]+\ln \left[\left(1+X^{2}\right) / 2\right]-2 \arctan (X)+\pi / 2, & -1.0 \leq z / L<0\end{cases}
$$

where $X=[(1-16 z) / L]^{0.25}$ and $L$ is the Obukhov length, which is defined as follows:

$$
L=-u_{*}^{3} T_{v} /\left(\kappa g \overline{w^{\prime} T_{v}^{\prime}}\right),
$$

with the friction velocity defined as

$$
u_{*}^{2}=\left({\overline{u^{\prime} w^{\prime}}}^{2}+{\overline{v^{\prime} w^{\prime}}}^{2}\right)^{0.5},
$$

where $T_{v}$ is the virtual temperature $(\mathrm{K})$ and can be replaced by the sonic temperature; $g=9.8 \mathrm{~m} \mathrm{~s}^{-2}$ is gravitational acceleration; $T_{v}^{\prime}$ is the fluctuation in virtual temperature; and $u^{\prime}, v^{\prime}$, and $w^{\prime}$ are wind fluctuations in the streamwise, lateral, and vertical directions, respectively. The effect of upwind land fetch near the tower on the lower part of the surface layer was also evaluated (Shir 1972; Rao et al. 1974; Wood 1982; Powell et al. 1996; Grachev et al. 2018). We conclude that the wind speeds at all four levels and turbulence characteristics at the upper three levels are from the nearshore surface layer, despite the tower being located at a coastal site. As a result, the wind speeds at all four levels are used to calculate wind speed at $10 \mathrm{~m}$ above the sea surface $u_{10}$, and the turbulence characteristics at the upper three levels are used to study the variations in friction velocity with wind speed and height.

Using the wind speed at four levels and the mean value of the Obukhov parameter $\left.(z / L)\right|_{\text {mean }}$ at the third and fourth levels, $u_{*}$ and $z_{0, n}$ can be obtained from Eq. (2). Thus, $u_{10}$ can be obtained by setting $z=10 \mathrm{~m}$. The neutral wind speed at $10 \mathrm{~m}$ above the sea surface under onshore wind conditions can be calculated as

$$
\begin{aligned}
& u_{10, n}=u_{10}+\delta u_{10}, \quad \text { with } \\
& \delta u_{10}=\frac{u_{*}}{\kappa} \psi\left[\left.(z / L)\right|_{10}\right] \approx \frac{u_{*}}{\kappa} \psi\left[\left.(z / L)\right|_{\text {mean }}\right] .
\end{aligned}
$$

It should be stressed that, in this study, friction velocities calculated by the eddy covariance method of Eq. (4b) and by the wind-profile method of Eq. (2), are comparable when $u_{10, n} \geq 9 \mathrm{~m} \mathrm{~s}^{-1}$.

After applying the quality-control procedure described above, wind speeds and directions at $10 \mathrm{~m}$ above the sea surface with an ATI of $10 \mathrm{~min}$ for each typhoon are shown in Fig. 3. We do not consider variations in wind direction with height and take them as those from the first level. Wind data corresponding to those in Fig. $2 b$ are shown in Fig. 3a. Wind speeds of larger than $9 \mathrm{~m} \mathrm{~s}^{-1}$ and wind directions of $15^{\circ}-210^{\circ}$ are shown in Fig. 3b. The data in Fig. $3 b$ are further divided into six subdatasets according to typhoon, wind speed, and direction, as shown in Table 1. An interesting phenomenon is that the surface layer seems to be in a nearly neutral state with increasing wind speeds, except that an unstable state exists for the data from $M G \_200$, where the winds are roughly perpendicular to the propagation directions of sea waves with longer wavelength.

\section{Observational results}

\section{a. Variations in $u_{*}$ with wind speed}

A scatterplot of $u_{*}$ versus wind speed with an ATI of $10 \mathrm{~min}$ is shown in Fig. 4 for the six subdatasets. In general, for wind directions of $30^{\circ}$ and $135^{\circ}$ (Figs. 4a,e), variations in $u_{*}$ with wind speed follow or are slightly greater than published results. For wind directions of $60^{\circ}$ (Figs. $4 \mathrm{~b}, \mathrm{~d}, \mathrm{f}$ ), variations in $u_{*}$ with wind speed are slightly smaller than the published results. For a wind direction of $200^{\circ}$ (Fig. 4c), variations in $u_{*}$ with wind speed are noticeably smaller than the published results. Clearly, wind direction has an effect on variations in $u_{*}$ with wind speed. This phenomenon can be explained by the form-drag theory in the air-sea momentum flux exchange study (Fang et al. 2018). Form drag is a major contributor to sea drag (Kudryavtsev et al. 1999; Makin and Kudryavtsev 1999; Donelan et al. 2012). Sea waves tend to propagate normal to the shoreline or isobaths because of the refraction effect as they approach the shoreline. As shown in Fig. 1, the propagation directions of sea waves in the local region were roughly the same as the wind direction for winds blowing $135^{\circ}$. Under this condition, the form drag caused by sea waves with longer wavelengths is comparable to that in the open-sea conditions. As a result, variations in $u_{*}$ with wind speed agree with published results (Fig. 4e). For a wind direction of $200^{\circ}$, it is roughly perpendicular to the 

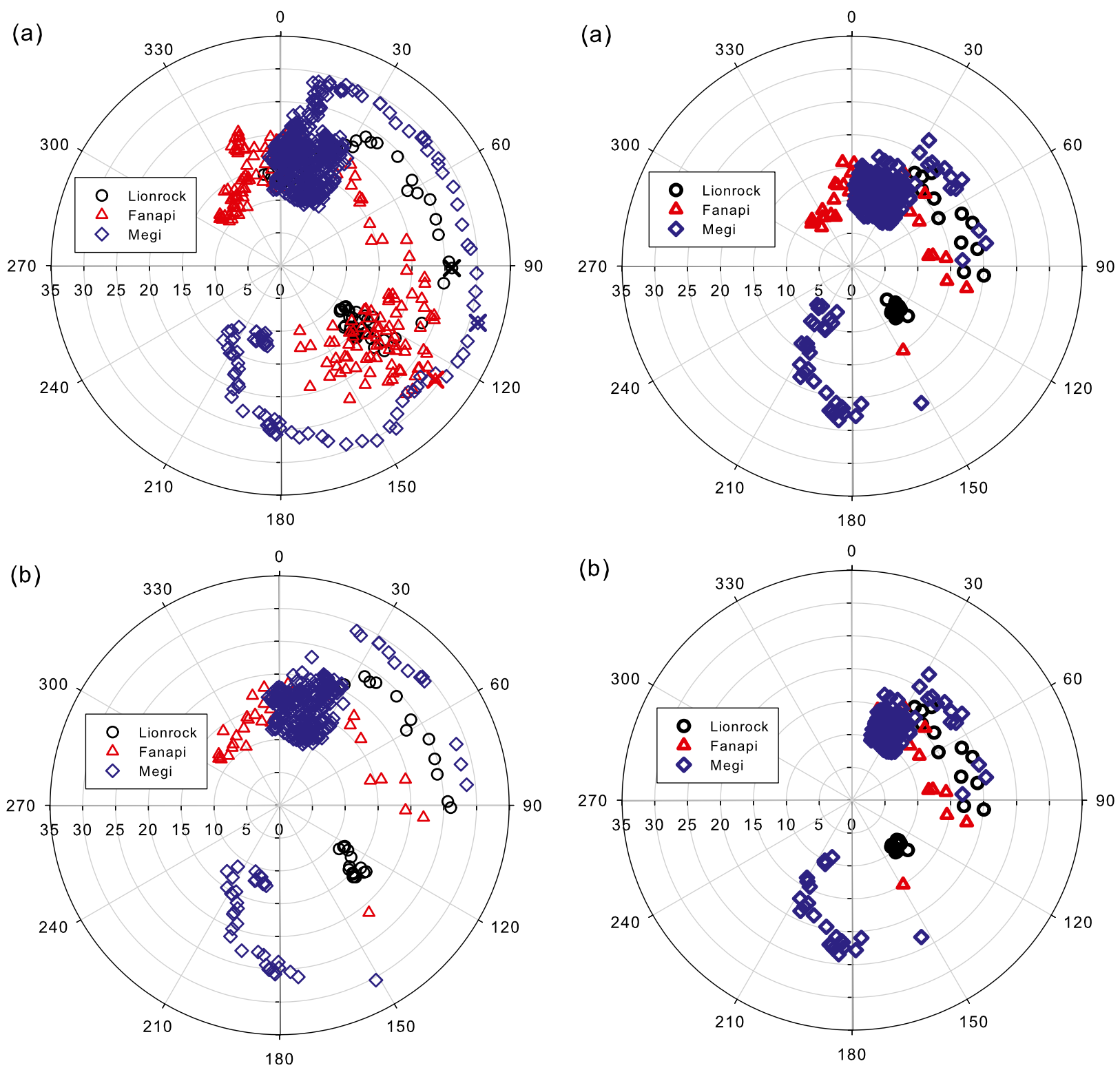

FIG. 2. Polar plots of wind speeds and directions from observations at the fourth level with an ATI of $10 \mathrm{~min}$ and for wind speeds higher than $10 \mathrm{~m} \mathrm{~s}^{-1}$ for each typhoon: (a) wind data prior to any quality control and (b) wind data featured by full profiles. In (a), landfall times (crosses) are shown for each typhoon with different colors. Wind data to the left (azimuth with small angle) of the crosses are before landfall; those to the right (azimuth with large angle) are after landfall.

propagation directions of sea waves with longer wavelengths, and the form drag contributed by these sea waves is negligible or makes up only a small portion of the total drag. As a result, variations in $u_{*}$ with wind speed are noticeably smaller than published results (Fig. 4c). The winds and the sea waves are in a cross state for wind directions of $60^{\circ}$ (angles from the propagation

FIG. 3. Polar plots of wind speeds and directions at $10 \mathrm{~m}$ above the sea surface with an ATI of 10 min for each typhoon: (a) wind data corresponding to those shown in Fig. $2 \mathrm{~b}$ and (b) wind data for wind directions of $15^{\circ}-210^{\circ}$ and $u_{10, n} \geq 9 \mathrm{~m} \mathrm{~s}^{-1}$. Wind speeds at $10 \mathrm{~m}$ above the sea surface were obtained using the wind-profile method.

directions of the sea waves to the wind directions are less than $90^{\circ}$ ). As a result, variations in $u_{*}$ with wind speed are slightly smaller than the published results (Figs. 4b,d,f). Last, the winds and the sea waves are in a counter state for wind directions of $30^{\circ}$ (angles from the propagation directions of the sea waves to the wind directions are larger than $90^{\circ}$ ). As a result, variations in $u_{*}$ with wind speed follow or are slightly greater than published results (Donelan et al. 1997). Another reason 
TABLE 1. Brief descriptions on the subdatasets. The averaging time interval is $10 \mathrm{~min}$.

\begin{tabular}{|c|c|c|c|c|}
\hline $\mathrm{Name}^{\mathrm{a}}$ & Typhoon & $\begin{array}{c}\text { Range of wind speed }\left(\mathrm{m} \mathrm{s}^{-1}\right) / \text { wind } \\
\text { direction }\left(^{\circ}\right)\end{array}$ & $\begin{array}{l}\text { Before or after } \\
\text { landfall time }\end{array}$ & Sample count \\
\hline LR_060_B_10 & Lionrock & $15.0-20.1 / 33.9-94.1$ & Before & 12 \\
\hline LR_135_A_10 & Lionrock & $9.1-11.4 / 130.8-140.2$ & After & 14 \\
\hline FN_060_B_10 & Fanapi & $11.7-17.7 / 82.5-101.0$ & Before & 10 \\
\hline MG_030_B_-10 & Megi & $9.0-16.8 / 16.1-41.5$ & Before & 152 \\
\hline MG_060_B_10 & Megi & $16.8-22.4 / 30.8-87.0$ & Before & 13 \\
\hline MG_200_A_10 & Megi & $9.2-23.5 / 176.1-208.7$ & After & 22 \\
\hline
\end{tabular}

${ }^{a}$ Naming rules: for UU_XXX_V_YY, UU is the typhoon name (LR is for Lionrock, FN is for Fanapi, and MG is for Megi), XXX is the mean observation azimuth ( 030 is for $30^{\circ}, 060$ is for $60^{\circ}, 135$ is for $135^{\circ}$, and 200 is for $\left.200^{\circ}\right)$, $\mathrm{V}$ is the observation time $(\mathrm{A}$ is for after landfall, and B is for before landfall), and YY is the ATI (10 is for $10 \mathrm{~min}$, and 01 is for $1 \mathrm{~min}$ ) (see Fig. 5 for 01).

may be the perturbed influence of the land upwind of the water body as wind blowing from the limited sea conditions. The altitude of the land upwind of the water body is about $200 \mathrm{~m}$ (indicated by the Google Map). As pointed out by Tieleman (1992), the turbulent characteristics may be enhanced by the large-scale topographic features' upwind fetch of about $100 \mathrm{~km}$. Thus, the assumption that the land upwind of the water body had little effect on the wind data may not be appropriated in this study. García-Nava et al. (2012) found that the relative direction of the wind and sea waves affects the airsea momentum flux exchange via form drag. Shabani et al. (2014) found a similar decreasing tendency going from winds blowing in the onshore direction (normal to the shoreline) to those blowing in the alongshore direction (parallel to the shoreline). The underlying surface is the surfzone, and the wind speed is lower than $14 \mathrm{~m} \mathrm{~s}^{-1}$, as compared with the underlying nearshore zone and wind speeds are higher than $9 \mathrm{~m} \mathrm{~s}^{-1}$ in this study.

Wind data with higher wind speeds are required to investigate the leveling off or decrease phenomenon on the variations in $u_{*}$ with wind speed. This can be realized by choosing an ATI of $1 \mathrm{~min}$. The rationale behind choosing an ATI of $1 \mathrm{~min}$ is as follows: the variation in friction velocity with wind speed, or the quantity $u_{*} / u_{10, n}$, is controlled by the roughness induced by sea waves under the assumption of a logarithmic wind profile. To the best of our knowledge, most published seawave spectra have a peak wave period no less than $0.5 \mathrm{rad} \mathrm{s}^{-1}$, corresponding to a period of $12.56 \mathrm{~s}$. Thus, an ATI of 1 min can be considered relatively long and can capture the representative characteristics of variations in friction velocity with wind speed, thereby extending the wind speed range of the observations. Figure 5 shows a scatterplot of $u_{*}$ versus wind speed with an ATI of $1 \mathrm{~min}$. Wind data from Megi and Fanapi were selected because they have a maximum wind speed higher than $25 \mathrm{~m} \mathrm{~s}^{-1}$ and thus provide a relatively larger range in wind speed. The friction velocities here are the mean values at the second, third, and fourth levels. As a result, variations in $u_{*}$ with wind speed can be taken as the mean variation in a thin layer from the second to fourth levels. It is evident that the friction velocity levels off at wind speeds of about $20 \mathrm{~m} \mathrm{~s}^{-1}$ in Fig. 5a, and it has a tendency to level off or decrease at wind speeds of about $20 \mathrm{~m} \mathrm{~s}^{-1}$ in Figs. $5 \mathrm{c}$ and $5 \mathrm{~d}$. The friction velocity may have a decrease tendency in Fig. 5b, although we cannot determine the critical wind speed for this phenomenon. The wind speed range may still be too small to make generalizations; however, our conclusions are supported by the fact that the wind data are from various subdatasets and wind directions. Figure 5 also shows a lower critical wind speed of $\sim 20 \mathrm{~m} \mathrm{~s}^{-1}$ as compared with the nearshore results of $26-30 \mathrm{~m} \mathrm{~s}^{-1}$ reported by Zhao et al. (2015). This may be caused by enhanced wave breaking induced by decreasing sea depth that lowers the critical wind speed as sea waves propagate toward the shoreline. This mechanism is discussed in detail by Zhao et al. (2015) and Fang et al. (2018).

\section{b. Variations in $u_{*}$ with height}

The boundary layer theory predicts that the friction velocity is zero at the top of the boundary layer or decreases with height. Banner et al. (1999) and French et al. (2007) showed that $u_{*}$ generally decreases with height under typhoon conditions and reported that the A\&D model can provide realistic estimates of the decrease in friction velocity with height. The mean rate of decrease from its surface value for $u_{*}$ in the lowest $100 \mathrm{~m}$ above the sea surface using the A\&D model is provided in Table 2. According to the A\&D model, the method for calculating the mean rate of decrease involves first obtaining the surface friction velocity $u_{* s}$ using each sample of the friction velocity. Then, the rate of decrease in the lowest $100 \mathrm{~m}$ above the sea surface can be obtained for the sample. Finally, the mean rate of decrease at each level is obtained by averaging the rates of decrease for all samples from that level. There is negligible difference among the various levels shown in 
(a)

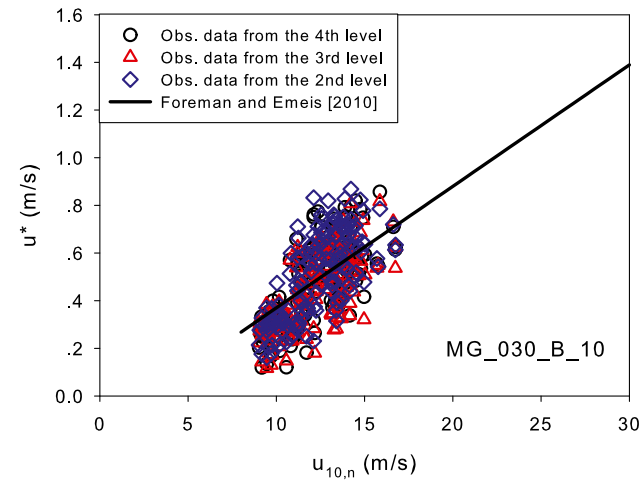

(c)

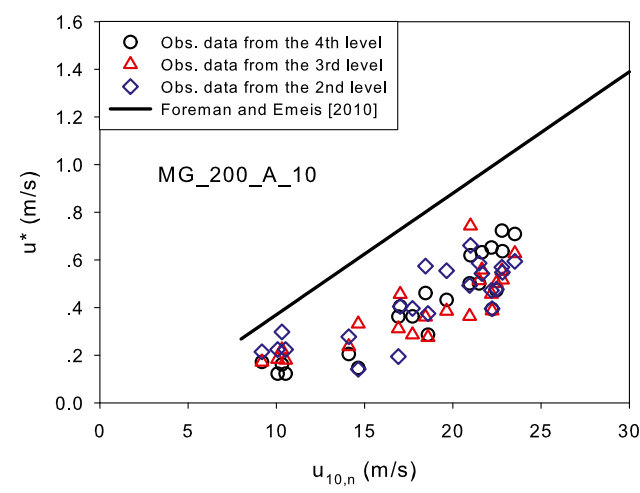

(e)

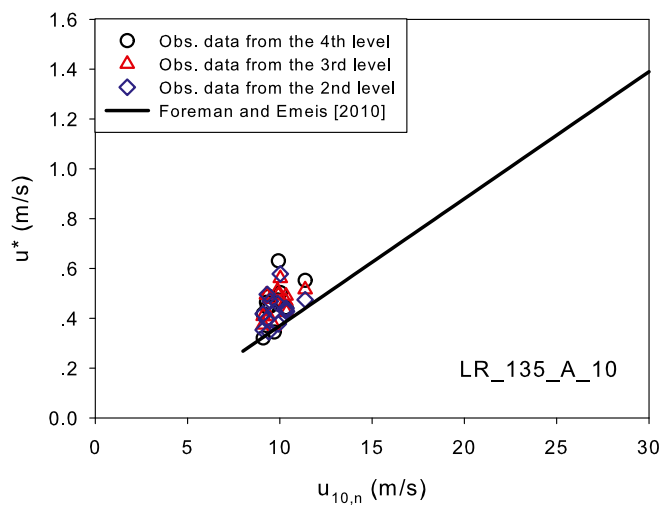

(b)

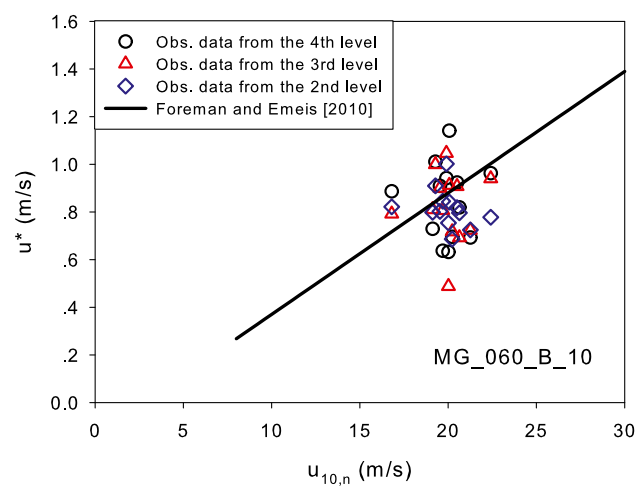

(d)

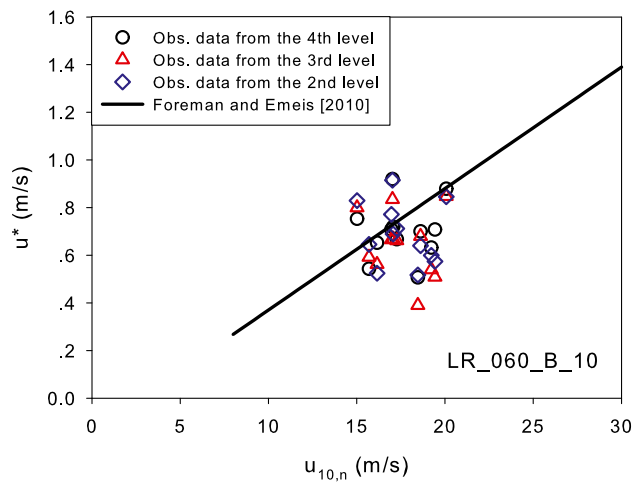

(f)

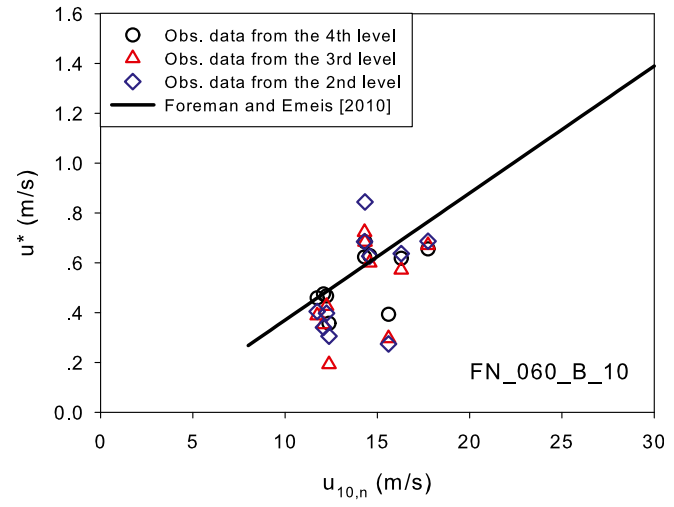

FIG. 4. Variations in $u_{*}$ with wind speed. The averaging time interval is $10 \mathrm{~min}$. Only moderate-to-strong wind speed range $\left(u_{10, n} \geq 8 \mathrm{~m} \mathrm{~s}^{-1}\right)$ was plotted for the results from Foreman and Emeis (2010).

Table 2. However, there exist some differences among the subdatasets, even for the same wind direction. The largest rate of decrease is observed for subdataset $\mathrm{MG}_{-}$ 200_A_10, for which the wind is roughly parallel to sea waves with longer wavelength.

Scatterplots of $u_{*}$ versus height are shown in Fig. 6 for the six subdatasets. We do not consider the effects of wind speed on the variations because each subdataset has a relatively small range of wind speed, except the subdataset shown in Fig. 6c. Boxplots and the mean value for each level are also shown in the figure. The mean and median values for each level are nearly identical, which implies that the distribution of dataset is symmetrical. Thus, the mean value can be used to describe the mean variations in $u_{*}$ with height as a first step. In general, the friction velocity does not always decrease with height from the second to fourth levels. This conclusion can also be supported by the scatterplot of friction velocity differences between the fourth or third levels and the second level, as shown in Fig. 7. 
(a)

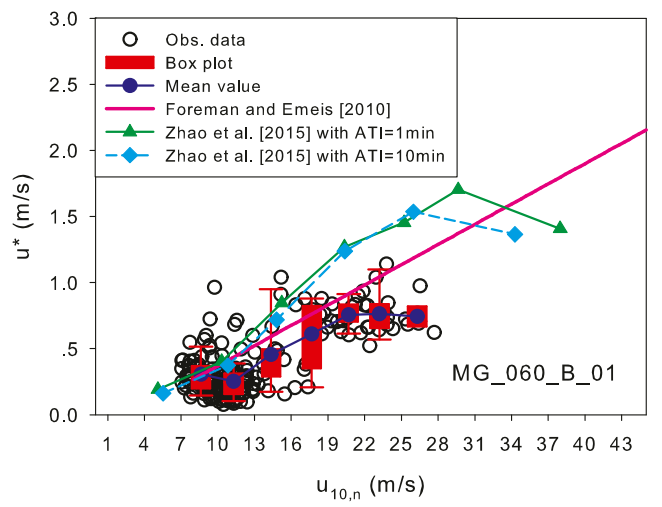

(c)

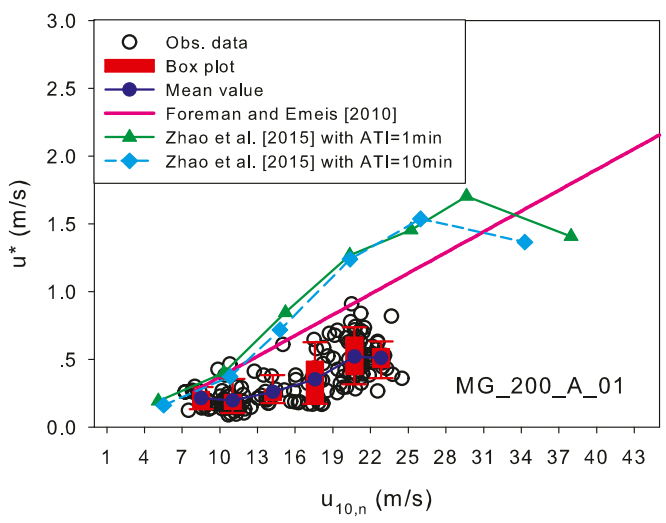

(b)

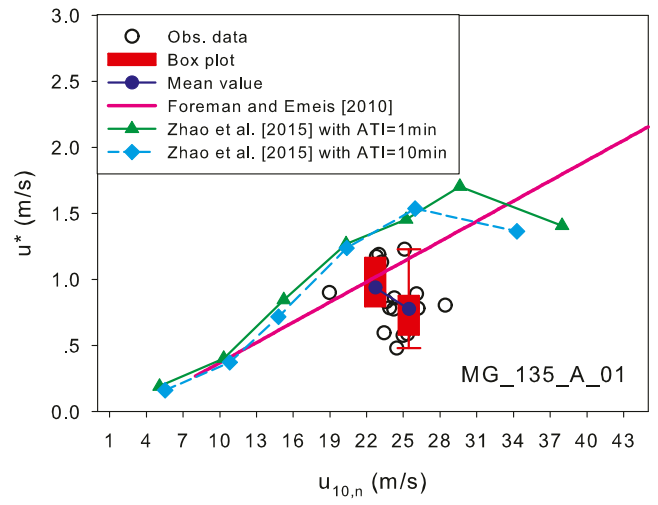

(d)

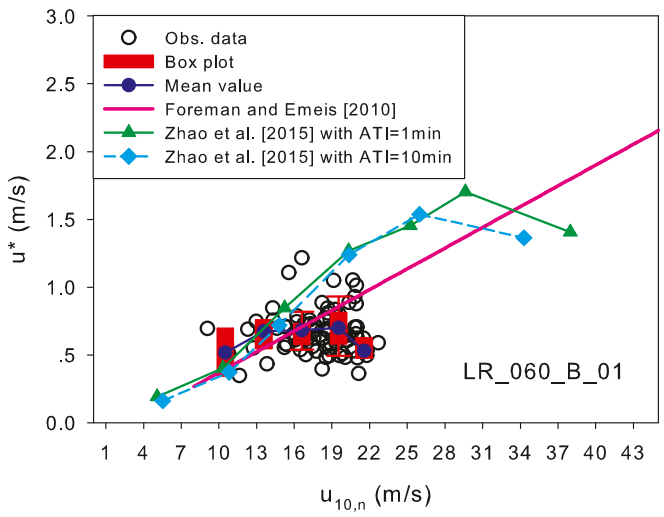

FIG. 5. Variations in $u_{*}$ with wind speed. The averaging time interval is $10 \mathrm{~min}$, and the wind speed bin size is $3 \mathrm{~m} \mathrm{~s}^{-1}$. Only moderate-to-strong wind speed range $\left(u_{10, n} \geq 8 \mathrm{~m} \mathrm{~s}^{-1}\right)$ was plotted for the results from Foreman and Emeis (2010). Friction velocities reported by Zhao et al. (2015) were obtained using the wind-profile method with wind speeds from $13.4,16.4,20.0,23.4$, and $31.3 \mathrm{~m}$ above the sea surface. The lower and upper whisker caps in the boxplots correspond to the 10th and 90th percentiles, respectively. The lower and upper box edges correspond to the 25 th and 75 th percentiles, respectively. Boxplots may lack caps for sample counts between 3 and 8 .

The positive relative value indicates that the friction velocity increases with height. It can be seen that a large portion of the samples has a positive relative value and can be even one time larger than the friction velocity at the second level (Fig. 7c). On the other hand, friction velocity decreases with height at higher friction velocities or wind speeds (Figs. 7a,e,f) or remains constant (Figs. 7b-d) in the thin layer. The mean rate of decrease in the lowest $100 \mathrm{~m}$ is also calculated based on the A\&D model using the mean friction velocity at each level shown in Fig. 6, and comparable results can be obtained as those shown in Table 2. These differences in the variation in friction velocity with height between the model and observations suggest that the boundary layer structure is complicated and that further investigation is needed in the future. In addition, it is not a reliable practice to simply adjust friction velocity using the A\&D model, at least for the dataset used in this study. We do

TABLE 2. Mean rate of decrease from its surface value for $u_{*}$ in the lowest $100 \mathrm{~m}$ above the sea surface (\%) for different typhoons and wind directions based on the A\&D model. Standard deviations are shown in parentheses. The averaging time interval is $10 \mathrm{~min}$.

\begin{tabular}{|c|c|c|c|c|c|c|}
\hline \multirow[b]{2}{*}{ Level (height above the sea surface) } & \multicolumn{2}{|c|}{ Lionrock } & \multirow{2}{*}{$\frac{\text { Fanapi }}{\text { FN_060_B_10 }}$} & \multicolumn{3}{|c|}{ Megi } \\
\hline & LR_060_B_10 & LR_135_A_10 & & MG_030_B_10 & MG_060_B_10 & MG_200_A_10 \\
\hline Second $(71.4 \mathrm{~m})$ & $5.22(0.95)$ & $8.06(1.05)$ & $7.60(2.91)$ & $7.93(3.34)$ & $4.33(0.40)$ & $9.73(4.69)$ \\
\hline Third $(89.4 \mathrm{~m})$ & $5.61(1.30)$ & $7.51(0.94)$ & $8.15(3.79)$ & $8.73(3.75)$ & $4.37(0.95)$ & $10.11(4.22)$ \\
\hline Fourth $(111.9 \mathrm{~m})$ & $5.06(0.84)$ & $7.62(1.25)$ & $6.67(1.52)$ & $8.30(3.81)$ & $4.24(0.78)$ & $10.80(6.53)$ \\
\hline
\end{tabular}


(a)

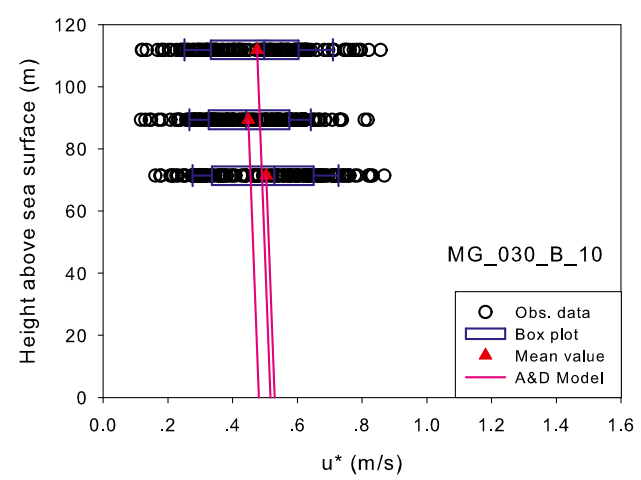

(c)

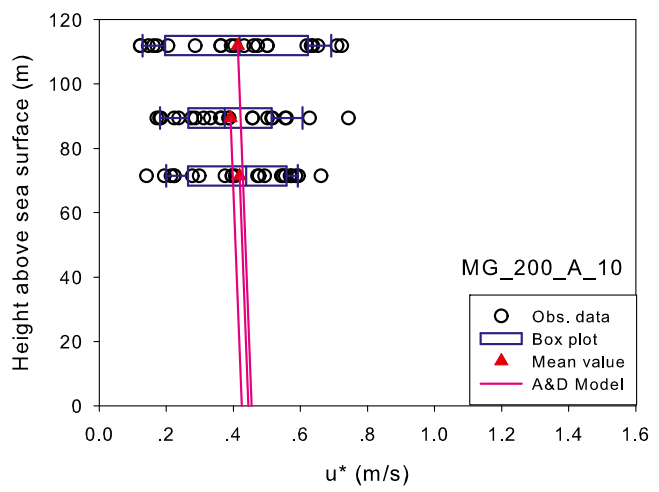

(e)

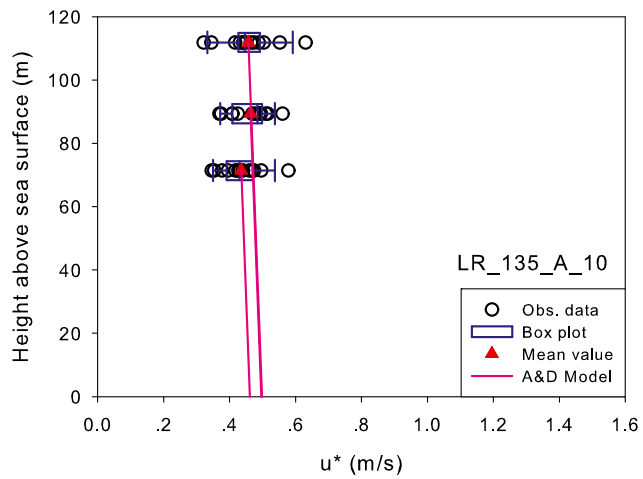

(b)

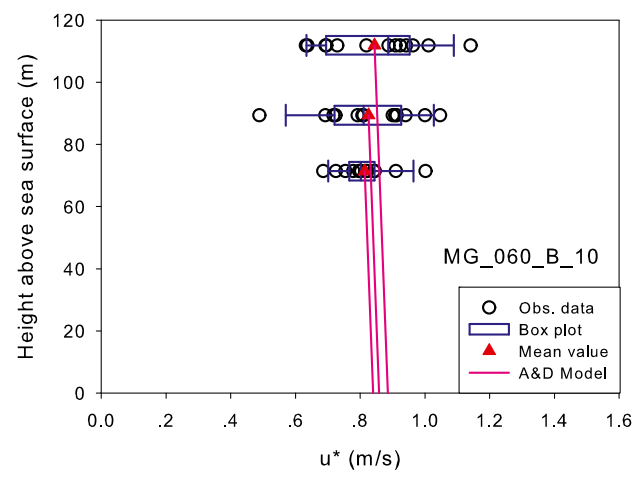

(d)

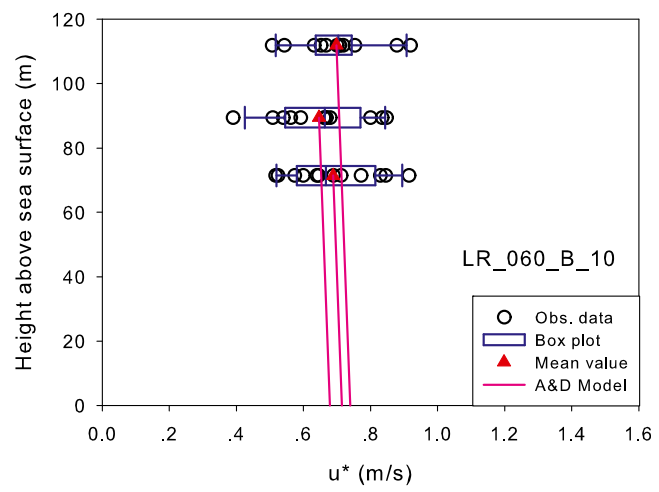

(f)

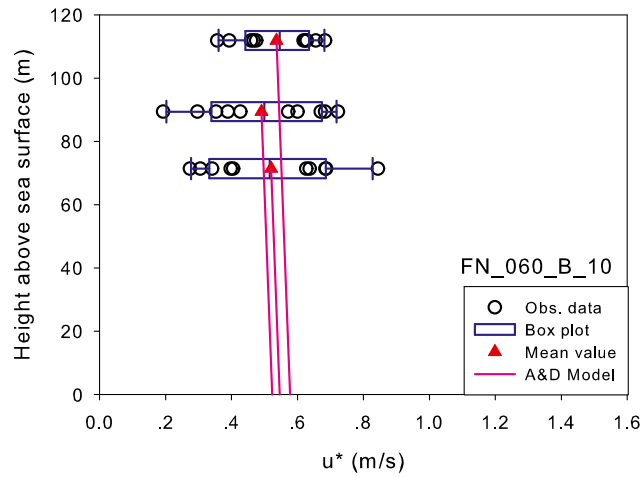

FIG. 6. Variations in $u_{*}$ with height. The averaging time interval is $10 \mathrm{~min}$. The left and right whisker caps in the boxplots correspond to the 10 th and 90 th percentiles, respectively.

not estimate surface-level values using linear regression because only three data points for each observation are available in this complicated boundary layer.

\section{c. Value of $u_{*}$ at the top of the surface layer}

Although the A\&D model has some deficiency as described above, we estimate the friction velocity at the top of the boundary layer according to the mean rate of decrease provided in Table 2. We believe that this will reduce the uncertainty by using the mean value. The boundary layer height must be known in advance for this estimation; however, various definitions of the boundary layer have been proposed (Zhang et al. 2011; Vickers and Mahrt 2004). The A\&D model is primarily validated in the surface layer. The surface-layer height $h$ can be estimated on the basis of Ekman theory as follows:

$$
h=C_{n} u_{*} / f,
$$

where $C_{n}$ is a nondimensional coefficient with values ranging from 0.01 to 0.05 (larger values are associated with neutral conditions) and $f$ is the Coriolis parameter. 
(a)

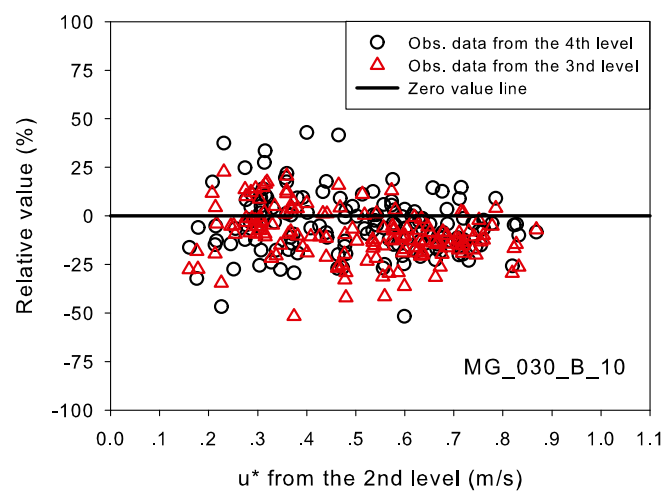

(c)

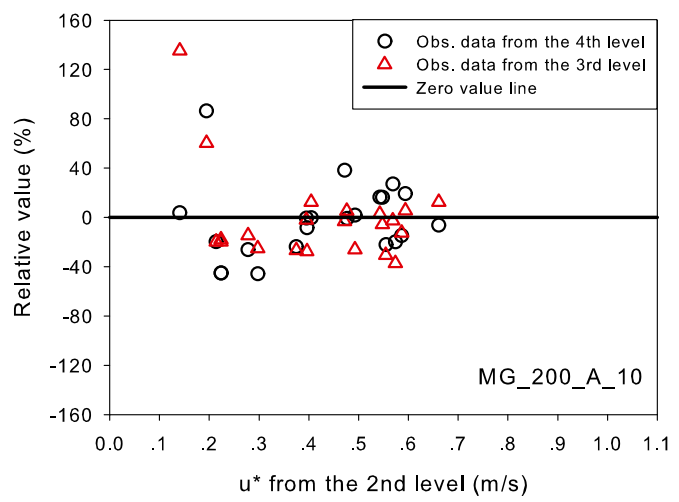

(e)

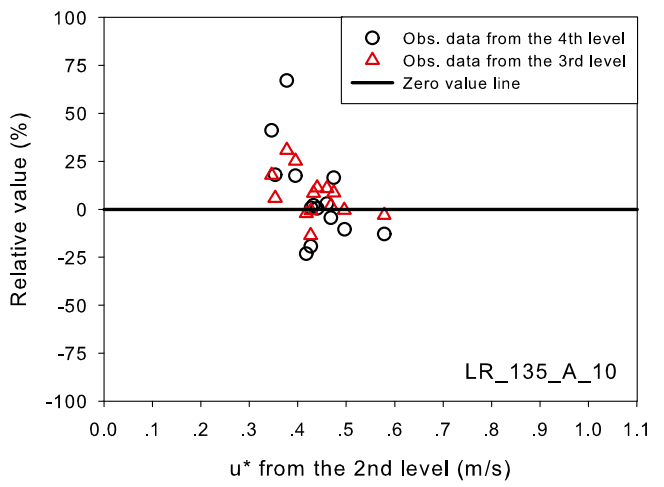

(b)

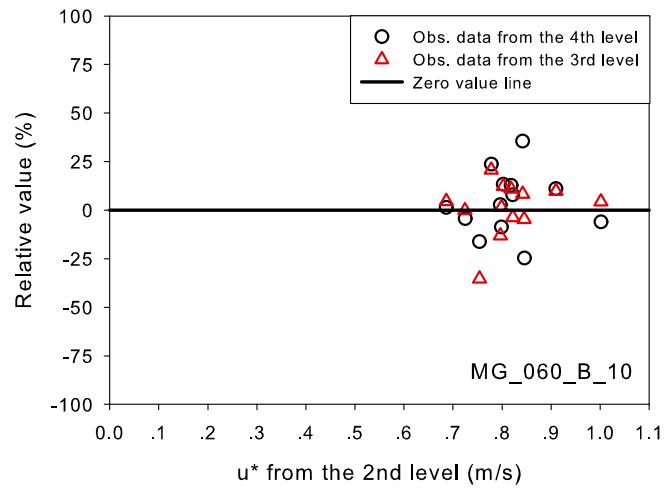

(d)

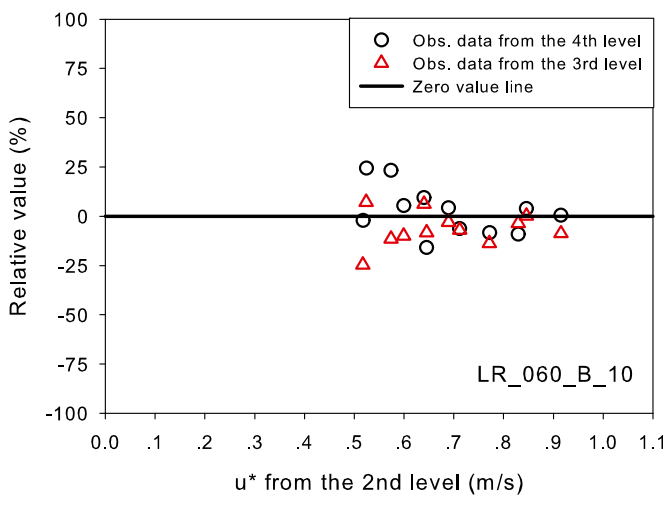

(f)

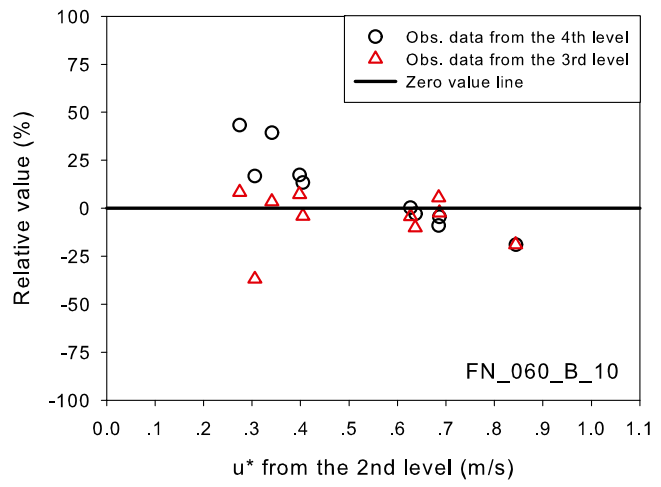

FIG. 7. Relative values of friction velocity differences between the fourth or third levels and the second level. The averaging time interval is $10 \mathrm{~min}$. The difference is defined as the friction velocity at the fourth or third levels minus that at the second level. The relative value is defined as this difference divided by the friction velocity at the second level.

We assume that the surface-layer height is about $10 \%$ of the ABL height, and thus $C_{n}=0.03$ (Tennekes 1973). For a specific site (constant $f$ ), Eq. (6) shows that the surface-layer height increases with higher friction velocity. This leads to controversial results for surfacelayer height within typhoons because higher friction velocity exists in the maximum wind speed zone near the eyewall, thus causing higher surface-layer heights according to Eq. (6). However, surface-layer heights are lower near the maximum wind speed zone than in the outer zones in typhoons, as demonstrated by Vickery et al. (2009). These lower surface-layer heights are also supported by the result from the wind profiles obtained by the GPS microsonde data as shown in Fig. 8a. The release sites of the GPS microsondes relative to the typhoon center are shown in Fig. 8b. A detailed description of the GPS microsonde measurements and the method used to obtain surface-layer heights in the 
(a)

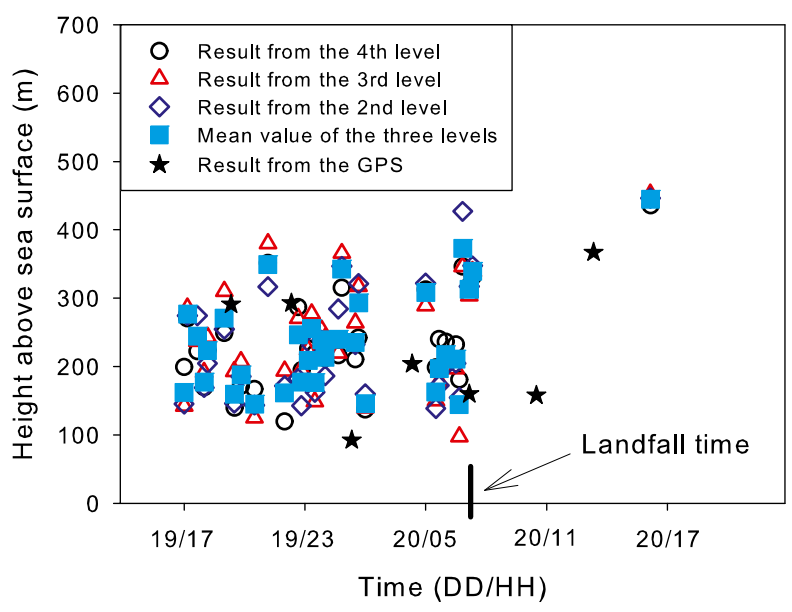

(b)

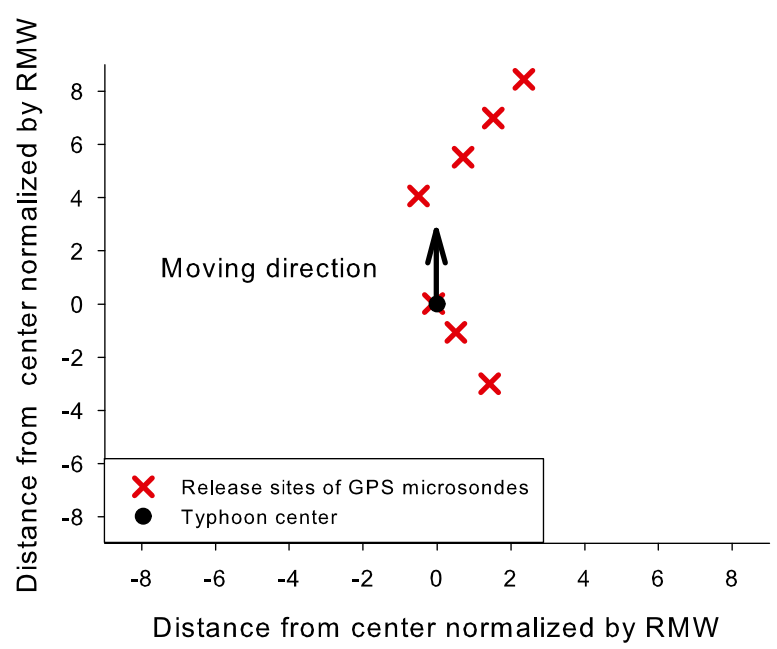

FIG. 8. (a) Temporal evolution of the surface-layer height around the time when Fanapi made landfall, and (b) typhoon-relative plots of the release sites of GPS microsondes. The averaging time interval is $10 \mathrm{~min}$. The release time is used for the GPS microsonde data shown in (a). The radial distance of the release sites (positions of the crosses) to the typhoon center (center of the figure) in (b) is normalized to the radius of the maximum wind speed (RMW). The radius of the maximum wind speed is from the Joint Typhoon Warning Center best-track data. The typhoon center location is from the China Meteorological Administration best-track data. Release times (UTC) for each GPS microsonde are as follows [from top to bottom in (b) for numbers 1-7): 111319 Sep, 141719 Sep, 171819 Sep, 201919 Sep, 230819 Sep, 022120 Sep, and 051120 Sep 2010.

typhoon can be found in the appendix. The temporal evolution of the surface-layer height around the time when Fanapi made landfall is calculated using Eq. (6) and also shown in Fig. 8a. The mean values of surfacelayer height predicted by Eq. (6) for the second, third, and fourth levels are 232.73, 242.29, and $238.13 \mathrm{~m}$, respectively. The mean value from the GPS microsonde data is $224.31 \mathrm{~m}$. In general, results from Eq. (6) and from the GPS microsonde data are comparable, at least for the mean values. Thus, mean values for surface-layer height based on Eq. (6) can be used to predict the friction velocity at the top of the surface layer, as shown in Table 3. The results in Table 3 are very close to that from Tennekes (1973) and comparable to that from French et al. (2007). This suggests that the friction velocity at the top of the surface layer in typhoons can be estimated by combining the A\&D model with the surface-layer height model [Eq. (6)], at least in a mean sense, considering the impossibility of accurate determination of the surface-layer height and the difficulty of direct observation of the friction velocity at the top of the surface layer.

\section{Conclusions}

Variations in friction velocity with wind speed and height were studied under moderate $\left(\geq 9 \mathrm{~m} \mathrm{~s}^{-1}\right)$-to-strong onshore wind conditions caused by three landfalling typhoons. Observations were made at a coastal site where a $100-\mathrm{m}$ tower was equipped with $20-\mathrm{Hz}$ ultrasonic anemometers at three heights. The four main conclusions of this study are as follows:

1) Wind direction has an effect on variations in friction velocity with wind speed. The variation in friction velocity with wind speed follows published results when the wind direction is normal to the shoreline in the local region and is lower than that when the wind direction is parallel to the shoreline. This phenomenon can be explained by the form-drag theory in the air-sea momentum flux exchange study. Lower critical wind speeds of $\sim 20 \mathrm{~m} \mathrm{~s}^{-1}$ exist for strong onshore winds because of the enhanced wave breaking induced by decreasing sea depth.

2) Friction velocity does not always decrease with height in the surface layer; however, friction velocity decreases or remains constant with height at higher friction velocities or higher wind speeds. A simple correction to the decrease of the friction velocity caused by height, based on the model in Anctil and Donelan (1996), is not reliable in this study.

3) GPS microsondes were released at a site located about $40 \mathrm{~km}$ southwest of the tower where Fanapi made landfall. A method to estimate surface-layer heights using wind-profile data is proposed based on the idea of mean boundary layer. Typical feature that lower surface-layer height near the typhoon centers was captured by the proposed method. Surface-layer heights calculated using the existing model based on Ekman dynamics are comparable to the results estimated using the proposed method, at least in terms of mean values. 
TABLE 3. Ratio of decrease in friction velocity at the top of the surface layer to the value at the surface for different wind directions. The averaging time interval is $10 \mathrm{~min}$.

\begin{tabular}{|c|c|c|c|c|c|c|}
\hline \multirow[b]{2}{*}{ Items } & \multicolumn{2}{|c|}{ Lionrock } & \multirow{2}{*}{$\frac{\text { Fanapi }}{\text { FN_060_B_10 }}$} & \multicolumn{3}{|c|}{ Megi } \\
\hline & LR_060_B_10 & LR_135_A_10 & & MG_030_B_10 & MG_060_B_10 & MG_200_A_10 \\
\hline $\begin{array}{l}\text { Mean rate of decrease per } \\
100 \mathrm{~m}(\%)^{\mathrm{a}}\end{array}$ & 5.30 & 7.73 & 7.47 & 8.32 & 4.35 & 10.21 \\
\hline Surface-layer height (m) & 342.92 & 228.67 & 260.86 & 240.82 & 418.92 & 206.32 \\
\hline Ratio of decrease (\%) & 18.2 & 17.7 & 19.5 & 20.0 & 18.22 & 21.1 \\
\hline
\end{tabular}

${ }^{\text {a }}$ Mean rate of decrease per $100 \mathrm{~m}$ is calculated by averaging the rate of decrease at the second, third, and fourth levels, shown in Table 2 .

4) Friction velocities at the top of the surface layer generally decrease by about $20 \%$ from the surface value under typhoon conditions, which is quite close to that from Tennekes (1973) and comparable to that from French et al. (2007).

Acknowledgments. This research was supported by the Ministry of Science and Technology of the People's Republic of China under Grants 2018YFB1501104 and 2015CB452806, the National Program on Global
Change and Air-Sea Interaction (GASI-IPOVAI-04), and the Natural Science Foundation of China under Grants 41475060 and 41775019. Further support was provided by the Key Program for International S\&T Cooperation Projects of China (2017YFE0107700), the Natural Science Foundation of Shanghai (Grant 19ZR1469200), and the Zhejiang Electric Power Co., LTD program (SGZJ0000KJJS1600445). The authors are indebted to the anonymous reviewers, who provided valuable suggestions that improved the paper. The data

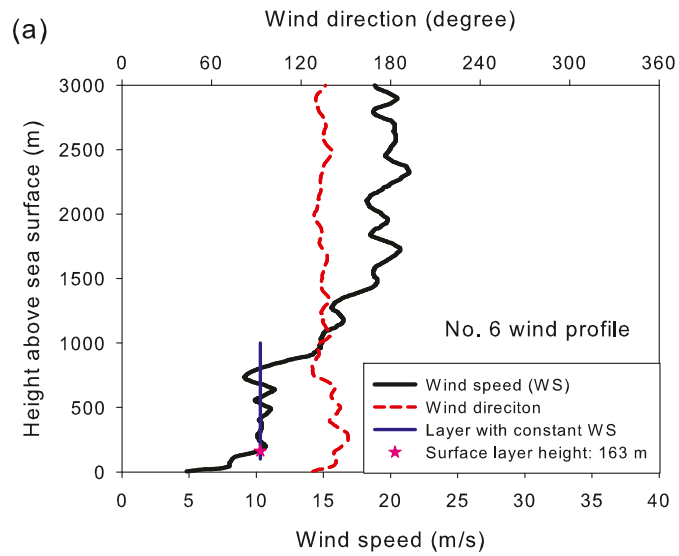

(b)

(c) Wind direction (degree)
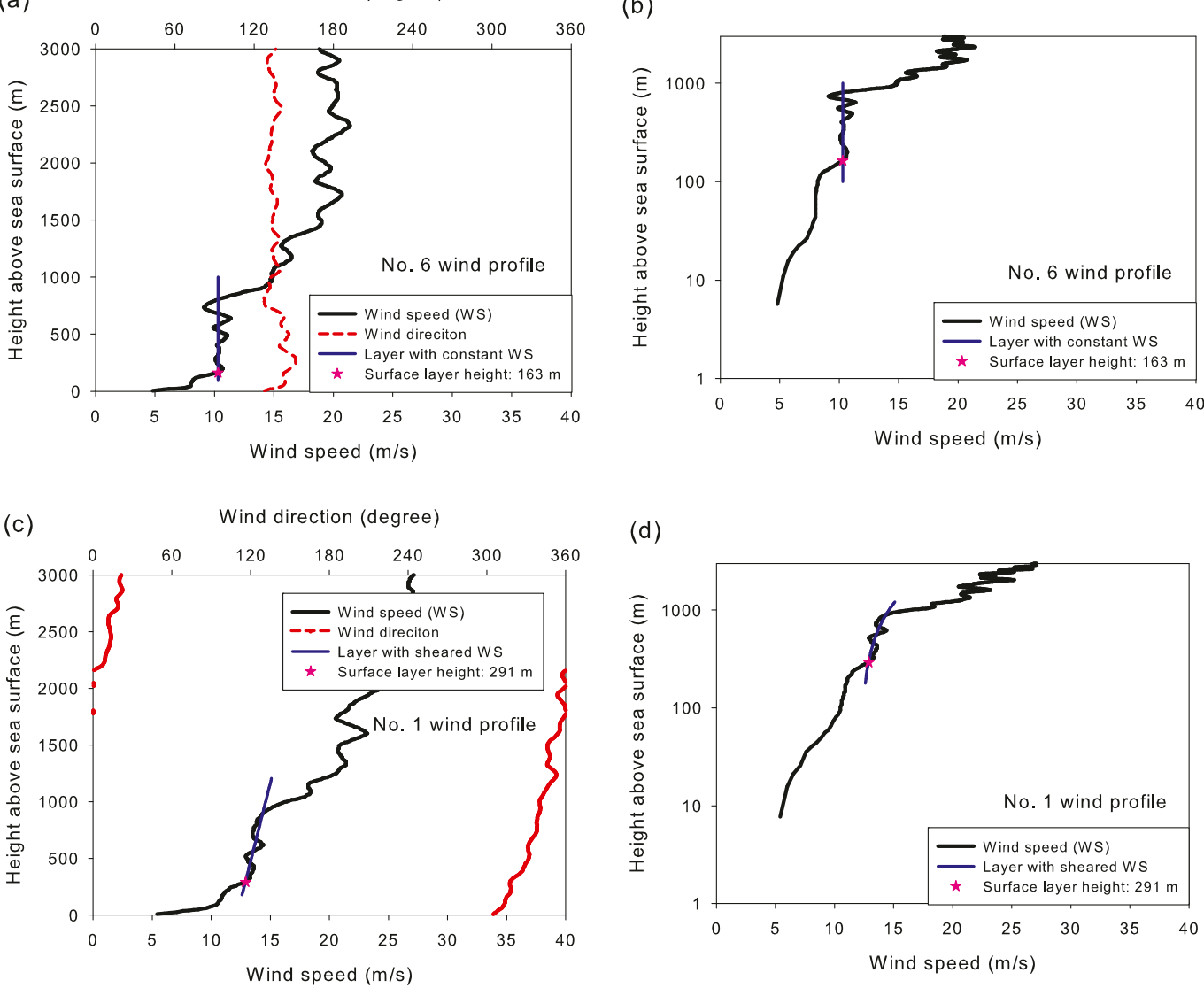

(d)

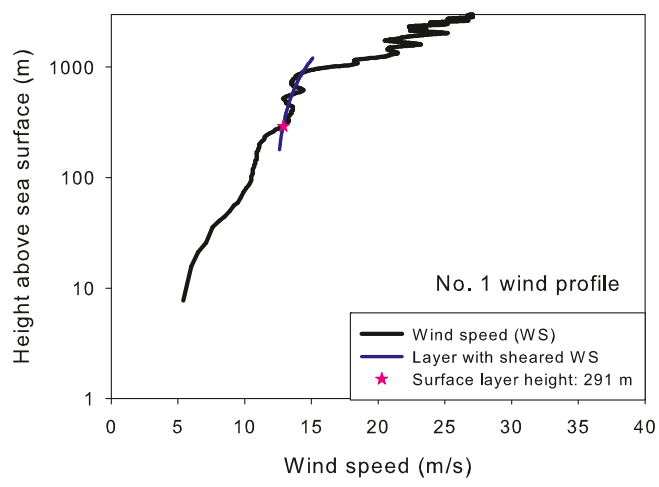

FIG. A1. Typical wind-profile structures for (a),(b) a constant wind speed layer over the surface layer and (c),(d) a sheared wind speed layer over the surface layer, using (left) linear coordinates and (right) logarithmic-linear coordinates. Surface-layer heights are also shown. 
that supported the figures and tables in this study can be accessed from freedomfpz@163.com.

\section{APPENDIX}

\section{GPS Microsonde Measurements and the Method Used to Obtain Surface-Layer Heights}

Seven GPS microsondes (Mark II) were released from a site (Gulei Harbor) located about $40 \mathrm{~km}$ southwest of the tower, where Fanapi made landfall (Fig. 1a). The microsondes were manufactured by Sippican. The rising speed of the microsondes was $4-5 \mathrm{~m} \mathrm{~s}^{-1}$, and the sampling frequency was $1 \mathrm{~Hz}$. Thus, a microsonde will need less than 2 min to reach a height of about $500 \mathrm{~m}$.

The method proposed to estimate the surface-layer height in typhoons is based on the idea of the average or mean boundary layer. The idea is widely used in wind field models for typhoons (Vickery et al. 2000) and was originally developed by Chow (1971). Our practice differs from Vickery et al. (2000) in that the average is made on the upper part of the boundary layer or above the surface layer in typhoon. For the upper part of the typhoon boundary layer, the wind field conforms to a gradient or geostrophic balance and moves horizontally with constant wind speed in depth. Gusts can be superimposed on the constant wind speed to describe a real wind field, as shown by Franklin et al. (2003). A surface layer exists below the constant wind speed layer. In this case, surface-layer height can be easily estimated for four wind profiles from the GPS microsonde data (numbers 4, 5, 6, and 7). A typical structure of the wind profiles (number 6) is shown in Figs. A1a and A1b. Furthermore, the layer may contain sheared wind speed rather than a constant wind speed in depth. Under these conditions, surface-layer heights can be identified for three wind profiles (numbers 1, 2, and 3). A typical structure of these wind profiles (number 1) is shown in Figs. A1c and A1d. All wind profiles (seven) were analyzed using this method. It seems that surface-layer height can be identified easily near the typhoon center. The general applicability of the proposed method should also be tested with more GPS microsonde data in future.

\section{REFERENCES}

Anctil, F., and M. A. Donelan, 1996: Air-water momentum flux observations over shoaling waves. J. Phys. Oceanogr., 26, 1344-1353, https://doi.org/10.1175/1520-0485(1996)026<1344: AMFOOS $>2.0 . \mathrm{CO} ; 2$.

Andreas, E. L, L. Mahrt, and D. Vickers, 2012: A new drag relation for aerodynamically rough flow over the ocean. J. Atmos. Sci., 69, 2520-2537, https://doi.org/10.1175/JAS-D-11-0312.1.
Banner, M. L., W. Chen, E. J. Walsh, J. B. Jensen, S. Lee, and C. Fandry, 1999: The Southern Ocean waves experiment. Part I: Overview and mean results. J. Phys. Oceanogr., 29, 2130-2145, https://doi.org/10.1175/1520-0485(1999)029<2130: TSOWEP $>2.0 . \mathrm{CO} ; 2$.

Bowen, A. J., and D. Lindley, 1977: A wind-tunnel investigation of the wind speed and turbulence characteristics close to the ground over various escarpment shapes. Bound.-Layer Meteor., 12, 259-271, https://doi.org/10.1007/BF00121466.

Chow, S., 1971: A Study of the Wind Field in the Planetary Boundary Layer of a Moving Tropical Cyclone. New York University, $58 \mathrm{pp}$.

Donelan, M. A., W. M. Drennan, and K. B. Katsaros, 1997: The air-sea momentum flux in conditions of wind sea and swell. J. Phys. Oceanogr., 27, 2087-2099, https://doi.org/10.1175/ 1520-0485(1997)027<2087:TASMFI>2.0.CO;2.

—, M. Curcic, S. S. Chen, and A. K. Magnusson, 2012: Modeling waves and wind stress. J. Geophys. Res., 117, C00J23, https:// doi.org/10.1029/2011JC007787.

Dyer, A. J., 1974: A review of flux-profile-relationships. Bound.Layer Meteor., 7, 363-372, https://doi.org/10.1007/BF00240838.

Edson, J., V. Jampana, and R. A. Weller, 2013: On the exchange of momentum over the open ocean. J. Phys. Oceanogr., 43, 15891610, https://doi.org/10.1175/JPO-D-12-0173.1.

Fairall, C. W., E. F. Bradley, J. E. Hare, A. A. Grachev, and J. B. Edson, 2003: Bulk parameterization of air-sea fluxes: Updates and verificationfor the COARE algorithm. J. Climate, 16, 571-591, https://doi.org/10.1175/1520-0442(2003)016<0571: $\mathrm{BPOASF}>2.0 . \mathrm{CO} ; 2$.

Fang, P., B. Zhao, Z. Zeng, H. Yu, X. Lei, and J. Tan, 2018: Effects of wind direction on variations in friction velocity with wind speed under conditions of strong onshore wind. J. Geophys. Res. Atmos., 123, 7340-7353, https://doi.org/ 10.1029/2017JD028010.

Foreman, R. J., and S. Emeis, 2010: Revisiting the definition of the drag coefficient in the marine atmospheric boundary layer. J. Phys. Oceanogr., 40, 2325-2332, https://doi.org/10.1175/ 2010JPO4420.1.

Franklin, J. L., M. L. Black, and K. Valde, 2003: GPS dropwindsonde wind profiles in hurricanes and their operational implications. Wea. Forecasting, 18, 32-44, https://doi.org/10.1175/ 1520-0434(2003)018<0032:GDWPIH >2.0.CO;2.

French, J. R., W. M. Drennan, J. A. Zhang, and P. G. Black, 2007: Turbulent fluxes in the hurricane boundary layer. Part I: Momentum flux. J. Atmos. Sci., 64, 1089-1102, https://doi.org/ 10.1175/JAS3887.1.

García-Nava, H., F. J. Ocampo-Torres, P. A. Hwang, and P. Osuna, 2012: Reduction of wind stress due to swell at high wind conditions. J. Geophys. Res., 117, C00J11, https://doi.org/ 10.1029/2011JC007833.

Grachev, A. A., L. S. Leo, H. J. S. Fernando, C. W. Fairall, E. Creegan, B. W. Blomquist, A. J. Christman, and C. M. Hocut, 2018: Airsea/land interaction in the coastal zone. Bound.-Layer Meteor., 167, 181-210, https://doi.org/10.1007/s10546-017-0326-2.

Guan, C. L., and L. Xie, 2004: On the linear parameterization of drag coefficient over sea surface. J. Phys. Oceanogr., 34, 28472851, https://doi.org/10.1175/JPO2664.1.

Jarosz, E., D. A. Mitchell, D. W. Wang, and W. J. Teague, 2007: Bottom-up determination of air-sea momentum exchange under a major tropical cyclone. Science, 315, 1707-1709, https://doi.org/10.1126/science.1136466.

Kudryavtsev, V. N., V. K. Makin, and B. Chapton, 1999: Coupled sea surface-atmosphere model: 2. Spectrum of short wind 
waves. J. Geophys. Res., 104, 7625-7639, https://doi.org/10.1029/ 1999JC900005.

Mahrt, L., D. Vickers, P. Frederickson, K. Davidson, and A.-S. Smedman, 2003: Sea-surface aerodynamic roughness. J. Geophys. Res., 108, 3171, https://doi.org/10.1029/2002JC001383.

Makin, V. K., and V. N. Kudryavtsev, 1999: Coupled sea surface-atmosphere model: 1 . Wind over waves coupling. J. Geophys. Res., 104, 7613-7623, https://doi.org/10.1029/ 1999JC900006.

Powell, M. D., S. H. Houston, and T. Reinhold, 1996: Hurricane Andrew's landfall in south Florida. Part I: Standardizing measurements for documentation of surface wind fields. Wea. Forecasting, 11, 304-328, https://doi.org/10.1175/1520-0434(1996) 011<0304:HALISF>2.0.CO;2.

- P. J. Vickery, and T. A. Reinhold, 2003: Reduced drag coefficient for high wind speeds in tropical cyclones. Nature, 422, 279-283, https://doi.org/10.1038/nature01481.

Rao, K. S., J. C. Wyngarrd, and O. R. Cote, 1974: The structure of the two-dimensional internal boundary layer over a sudden change of surface roughness. J. Atmos. Sci., 31, 738-746, https://doi.org/ 10.1175/1520-0469(1974)031<0738:TSOTTD>2.0.CO;2.

Shabani, B., P. Nielsen, and T. Baldock, 2014: Direct measurements of wind stress over the surf zone. J. Geophys. Res. Oceans, 119, 2949-2973, https://doi.org/10.1002/2013JC009585.

Shir, C. C., 1972: A numerical computation of air flow over a sudden change of surface roughness. J. Atmos. Sci., 29, 304-310, https://doi.org/10.1175/1520-0469(1972)029<0304: ANCOAF $>2.0 . \mathrm{CO} ; 2$.

Tennekes, H., 1973: The logarithmic wind profile. J. Atmos. Sci., 30, 234-238, https://doi.org/10.1175/1520-0469(1973)030<0234: TLWP $>2.0 . C O ; 2$.

Tieleman, H. W., 1992: Wind characteristics in the surface layer over heterogeneous terrain. J. Wind Eng. Ind. Aerodyn., 41, 329-340, https://doi.org/10.1016/0167-6105(92)90427-C.
Vickers, D., and L. Mahrt, 2004: Evaluating formulations of stable boundary layer height. J. Appl. Meteor., 43, 1736-1749, https:// doi.org/10.1175/JAM2160.1.

Vickery, P. J., P. F. Skerlj, A. C. Steckley, and L. A. Twisdale, 2000: Hurricane wind field model for use in hurricane simulations. J. Struct. Eng., 126, 1203-1221, https://doi.org/10.1061/(ASCE) 0733-9445(2000)126:10(1203).

_, D. Wadhera, M. D. Powell, and Y. Z. Chen, 2009: A hurricane boundary layer and wind field model for use in engineering applications. J. Appl. Meteor. Climatol., 48, 381-405, https://doi.org/10.1175/2008JAMC1841.1.

Wood, D. H., 1982: Internal boundary layer growth following a step change in surface roughness. Bound.-Layer Meteor., 22, 241244, https://doi.org/10.1007/BF00118257.

Zeng, Z. H., Y. Q. Wang, Y. H. Duan, L. S. Chen, and Z. Q. Gao, 2010: On sea surface roughness parameterization and its effect on tropical cyclone structure and intensity. Adv. Atmos. Sci., 27, 337-355, https://doi.org/10.1007/s00376-009-8209-1.

Zhang, J. A., W. M. Drennan, P. G. Black, and J. R. French, 2009: Turbulence structure of the hurricane boundary layer between the outer rainbands. J. Atmos. Sci., 66, 2455-2467, https:// doi.org/10.1175/2009JAS2954.1.

— R. F. Rogers, D. S. Nolan, and F. D. Marks Jr., 2011: On the characteristic height scales of the hurricane boundary layer. Mon. Wea. Rev., 139, 2523-2535, https://doi.org/10.1175/ MWR-D-10-05017.1.

Zhang, R., H. Jian, W. Xin, A. Zhang Jun, and H. Fei, 2016: Effects of precipitation on sonic anemometer measurements of turbulent fluxes in the atmospheric surface layer. J. Ocean Univ. China, 15, 389-398, https://doi.org/10.1007/s11802-016-2804-4.

Zhao, Z.-K., C.-X. Liu, Q. Li, G.-F. Dai, Q.-T. Song, and W.-H. Lv, 2015: Typhoon air-sea drag coefficient in coastal regions. J. Geophys. Res. Oceans, 120, 716-727, https://doi.org/10.1002/ 2014JC010283. 